\title{
Analysis of Thermal Characteristics for Spindle System of the KSMC1250 CNC Machining Center
}

\author{
Xiaozhong Ren ${ }^{1, a}$, Jing Dai ${ }^{1, b}$, Mingde Duan ${ }^{1, \mathrm{c}}$,Haichao Zang ${ }^{1, \mathrm{~d}}$, \\ Zhuangya Zhang ${ }^{1, e}$ and Hezeng Wang ${ }^{2, f}$ \\ ${ }^{1}$ School of Mechatronic Engineering, Henan University of Science and Technology, Luoyang, \\ 471003, China \\ ${ }^{2}$ YTO (Luoyang) KINTRA Equipment Science and Technology Co. Ltd., Luoyang, 471003, China \\ aren_xiaozhong@126.com, bdaijing1121@163.com, 'duan_mingde@163.com, \\ dzhc19921021@163.com, e'zhangzhuangya@126.com, 'whz196610@163.com
}

Keywords: Spindle system; Thermal characteristics; Thermal deformation

\begin{abstract}
As a core component of precision CNC machine tool, spindle's thermal characteristics affect the machining accuracy of the machine tool. In order to understand the influence of temperature increase on the deformation of the spindle system, the simulation model of the spindle system is established by determining and calculating heat sources and boundary conditions of the spindle system. The finite element analysis method is used to obtain the distribution of steady state temperature field and the condition of thermal deformation. The results of analysis provide the foundation for improvement and optimization of the vertical machining center.
\end{abstract}

\section{Introduction}

Manufacturing industry is a pillar industry of the national economy and an important manifestation of the national creativity, competitiveness and comprehensive national strength of the important embodiment. With the continuous development of high-tech, manufacturing technology has unprecedented new progress. CNC machine tool reflects the current mainstream of the world machine tool. It is important indicators of the level of mechanical manufacturing work and plays an important role in the core in advanced manufacturing technology. Higher requirements are put forward for accuracy of $\mathrm{CNC}$ machine tool. A large number of studies show that one of the main factors affecting the machining ac-curacy of high-speed machine tools is thermal error, which accounts for $40 \% \sim 70 \%$ of the total machine tool error[1]. Therefore, it is very important to study the thermal characteristics of CNC machine tool spindle system to improve the machining precision, which has been paid wide attention.

Jong-Jin Kim, et al,[2] made a finite element analysis of the high-speed operating spindle, mainly to explore the linear thermal expansion by thermal de-formation and tool's relative movement. ZHANG Bolin[3], et al, tested and analyzed the thermal characteristics of the high-speed spindle, and explored the main factors influencing the hot-state characteristics of the high-speed spindle. Liu Zhifeng[4], et al, considered the influence of thermistor, and studied the influence of contact thermal resistance on the thermal characteristics of the spindle. Zou Liyun[5], et al, used the finite element analysis to analyze the thermal characteristics of precision CNC turning center. Liu Junfeng[6], et al, studied the dynamic characteristics of the spindle based on the thermo-mechanical coupling model, and the optimization scheme is put forward.

In this paper, the KSMC1250 vertical machining center's spindle system is taken as the research object. The finite element analysis model is established to analyze the thermal stability and deformation of the spindle system. The increase of temperature and deformation of spindle system are found. These provides an important basis for improvement. 


\section{The Basic Theory of Thermal Steady State Analysis}

For steady-state thermal analysis, if the system's net heat flow rate is 0 . The heat that flows into the system and the heat generated by the system itself is equal to the heat flowing out of the system. The temperature of any node in steady-state thermal analysis does not change with time. The energy balance equation for steady-state thermal analysis is

$$
[\mathrm{K}]\{\mathrm{T}\}=\{\mathrm{Q}\}
$$

Where: $[\mathrm{K}]$ is the conduction matrix, including the thermal conductivity, convection coefficient and shape factor; $\{\mathrm{T}\}$ is the node temperature vector; $\{\mathrm{Q}\}$ is the node heat flow rate vector, including heat generation.

According to the reference[7,8], the global stiffness matrix $[\mathrm{K}]$ and the load vector can be derived from the boundary condition and the load combined with the thermal stress analysis

$$
\begin{aligned}
& {[\mathrm{K}]=\sum[\mathrm{K}]^{\mathrm{e}}} \\
& \mathrm{P}=\sum\{\mathrm{P}\}^{\mathrm{e}}+\sum\{\mathrm{P}\}_{\mathrm{T}}^{\mathrm{e}}
\end{aligned}
$$

Where, $[\mathrm{K}]^{\mathrm{e}}$ is the unit stiffness, $\{\mathrm{P}\}^{\mathrm{e}}$ is the load of element node, $\{\mathrm{P}\}_{\mathrm{T}}^{\mathrm{e}}$ is the thermal load of element node.

According to the displacement model, the displacement of the node can be deduced from the equilibrium condition, the variational principle and the Hooke's law which is $[\mathrm{K}]\{\partial\}=\{\mathrm{P}\}$. The total strain and thermal deformation are calculated by the displacement $\{\partial\}_{\mathrm{T}}^{\mathrm{e}}$ and temperature increase $\{\Delta \mathrm{T}\}^{\mathrm{e}}$ of the node. The final thermal stress expression is

$$
\{\sigma\}=[\mathrm{D}]\left(\{\varepsilon\}-\{\varepsilon\}_{\mathrm{r}}\right)
$$

Where, [D] is the elastic matrix.

\section{Boundary Conditions of Thermal Analysis}

The spindle system is mainly composed of main shaft, front bearing, back bearing, bearing spacer and other sealing elements. The simplified spindle structure is shown in Fig. 1.

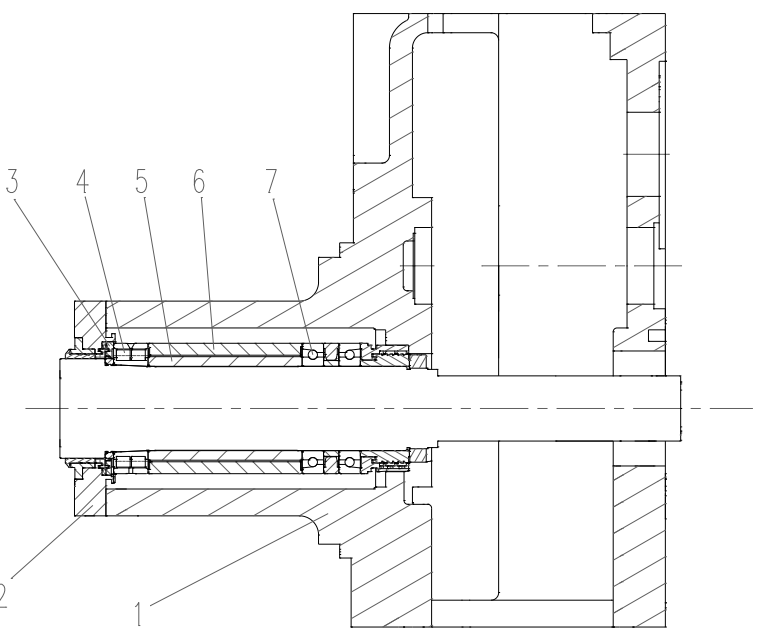

Figure 1. Structural sketch of the spindle system

1. Spindle box 2. End cover 3. Waterproof labyrinth 4. Front bearing 5. Inner spacer 6. Outer sleeve 7. Back bearing 
Calculation for Heat Source. In the CNC machining center processing, the spindle system has two main heat sources: cutting heat and friction heat of spindle bearing. As the cutting heat can be removed in time by the cutting fluid and coolant, so the bearing friction is considered merely[9] According to Palmgren formula[10] for friction moment, the spindle bearing heat

$$
\mathrm{H}_{\mathrm{f}}=1.047 \times 10^{-4} \mathrm{M} \cdot \mathrm{n}
$$

Where, $\mathrm{n}$ is the bearing speed, $\mathrm{r} / \mathrm{min} ; \mathrm{M}$ is the total friction torque of the bearing, $\mathrm{N} \cdot \mathrm{mm}$; calculation formula of total friction torque

$$
\mathrm{M}=\mathrm{M}_{1}+\mathrm{M}_{v}
$$

Where, $M_{1} M 1$ is the friction torque caused by the load; $M_{v}$ is the friction torque due to lubrication.

Friction torque caused by bearing load

$$
\begin{aligned}
& \mathrm{M}_{1}=\mathrm{f}_{1} \mathrm{~F}_{\beta} \mathrm{d}_{\mathrm{m}} \\
& \mathrm{f}_{1}=\mathrm{z}\left(\frac{\mathrm{P}_{0}}{\mathrm{C}_{0}}\right)^{\mathrm{y}}
\end{aligned}
$$

Where, $\mathrm{f}_{1}$ is the coefficient associated with the bearing structure and load; $\mathrm{F}_{\beta}$ is the equivalent static load for the bearing, $\mathrm{N} ; \mathrm{d}_{\mathrm{m}}$ is the pitch diameter of the bearing, $\mathrm{mm} ; \mathrm{P}_{0}$ is the equivalent static load of the bearing, $\mathrm{N}$; $\mathrm{C}_{0}$ is the rated static load, $\mathrm{N} ; \mathrm{z}, \mathrm{y}$ is the coefficient associated with the bearing type.

Bearing friction caused by friction torque

When $\mathrm{v}_{0} \mathrm{n} \geq 2000$

$$
\mathrm{M}_{v}=10^{-7} \mathrm{f}_{0}\left(\mathrm{v}_{0} \mathrm{n}\right)^{\frac{2}{3}} \mathrm{~d}_{\mathrm{m}}^{3}
$$

When $\mathrm{v}_{0} \mathrm{n}<2000$

$$
\mathrm{M}_{v}=160 \times 10^{-7} \mathrm{f}_{0} \mathrm{~d}_{\mathrm{m}}^{3}
$$

Where, $\mathrm{f}_{0}$ is the empirical coefficient associated with the type of bearing and the lubrication method; $\mathrm{v}_{0}$ is the kinematic viscosity of the lubricant, $\mathrm{cSt}$.

The specific parameters of the front and rear bearings in this paper are shown in Table 1

Table 1 Bearing parameters

\begin{tabular}{|c|c|c|}
\hline Parameters & Front bearing & Back bearing \\
\hline Bearing type & Double row cylindrical roller bearings & Angular contact ball bearings \\
\hline Outer diameter $[\mathrm{mm}]$ & 170 & 170 \\
\hline Inter diameter [mm] & 110 & 110 \\
\hline Pitch circle diameter [mm] & 140 & 140 \\
\hline Width [mm] & 45 & 28 \\
\hline Roller diameter [mm] & 14.9 & 12 \\
\hline The number of rollers & $18^{*} 2$ & 18 \\
\hline Contact angle $\left[{ }^{\circ}\right]$ & $/$ & 18 \\
\hline
\end{tabular}

During the operation of the machining center, the rolling element can be equivalent to a ring because of the high speed of bearing. Its cross-sectional area is equal to the rolling body cross-sectional area. Therefore, the bearing's heat generation rate can be calculated 


$$
\mathrm{q}=\frac{\mathrm{Q}}{\mathrm{V}}
$$

Where, $\mathrm{Q}$ is the bearing heat, $\mathrm{W}$; $\mathrm{V}$ is the volume of equivalent ring, $\mathrm{m}^{3}$.

Calculation for Thermal Boundary Condition. Heat transfer involves heat transfer, heat convection and heat radiation. For the spindle system, the spindle bearing temperature increase is relatively small, and the heat of heat radiation is small. The heat radiation is only considered temporarily. Therefore, the thermal conduction and thermal convection are only considered for the thermal system analysis of the spindle system. Convective heat is the phenomenon that heat transfer between the fluid and the solid surface when the fluid flows through the solid. In the operation of the spindle system, the main convection heat transfers are between the outer cover and the cooling oil, between bearing and compressed air, and between spindle's static surface and ambient air.

The heat transfer coefficient can be based on the Nouchert criterion[11], the formula is

$$
\alpha=\frac{\mathrm{N}_{\mathrm{u}} \lambda}{\mathrm{L}}
$$

Where, $\mathrm{W}$ is the heat transfer coefficient of the fluid, $\mathrm{W} /\left(\mathrm{m} \cdot{ }^{\circ} \mathrm{C}\right), \mathrm{L}$ is the size of the specimen, $\mathrm{m}$. The Nusselt number is calculated as

$$
\begin{aligned}
& \mathrm{N}_{\mathrm{u}}=\mathrm{C}(\mathrm{Gr} \cdot \mathrm{Pr})^{\mathrm{n}} \\
& \mathrm{Gr}=\frac{\mathrm{gL}{ }^{3} \beta \Delta \mathrm{t}}{v^{2}}
\end{aligned}
$$

Where, $\mathrm{Gr}$ is the Gracelonian quasi-number; $\mathrm{Pr}$ is the Prandtl number; $\mathrm{C}, \mathrm{n}$ is the value associated with the fluid motion and the surface orientation; $g$ is the gravitational acceleration, $\mathrm{m} / \mathrm{s}^{2} ; \beta$ is the volume expansion coefficient for the fluid; $v$ is the fluid kinematic viscosity, $\mathrm{m}^{2} / \mathrm{s}$.

The heat transfer between the stationary surface of the spindle system and the surrounding air is complex. It belongs to the compound heat transfer. Therefore, it is difficult to accurately calculate the heat transfer coefficient of the stationary surface of the spindle system. According to the literature [12], the heat transfer coefficient between air and the outer surface of the spindle system is $9.7 \mathrm{~W} /\left(\mathrm{m}^{2} \cdot{ }^{\circ} \mathrm{C}\right)$.

\section{Establishment of Finite Element Model}

In this paper, the spindle system of KSMC1250 vertical CNC machining center is taken as the research object. The 3D solid model of spindle system is established in CATIA. In the process of finite element modeling, the small features that have little effect on the system temperature are simplified. For example, chamfers and fillets, and the features which have little impact of the structure, such as the screw holes, positioning holes, keyways and other features.

Tetrahedral elements are selected to generate mesh. Turn the relevance to 100 to encrypt the grid density in order to ensure the accuracy of analysis. The finite element analysis model which has been generated mesh is shown in Fig. 2. It has 704075 nodes and 384121 elements. The grid quality is checked and Tet10 which can show grid quality is 0.78 on the average in Fig. 3. The grid quality can meet the accuracy for analysis. And then the material parameters of spindle system are set, as shown in Table 2. Thermal load and thermal boundary conditions are added in the finite element model. The analysis conditions are as follows: the ambient temperature is $20{ }^{\circ} \mathrm{C}$, the spindle speed is $6000 \mathrm{r} / \mathrm{min}$, the initial temperature of the spindle system is $20{ }^{\circ} \mathrm{C}$. 


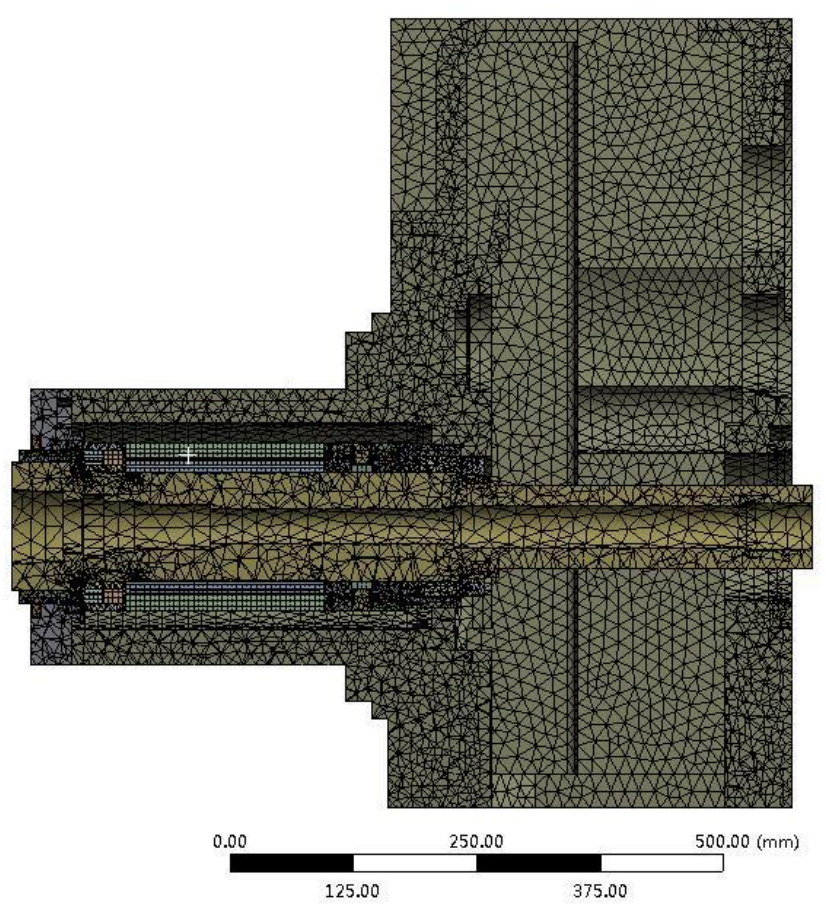

Figure 2. Finite model of the spindle system



Figure 3. Mesh quality

The material properties of the components of the spindle system are shown in Table 2

Table 2 Bearing parameters

\begin{tabular}{|c|c|c|c|c|c|c|c|}
\hline Name & Material & Density $/\left(\mathrm{kg} / \mathrm{m}^{3}\right)$ & $\begin{array}{c}\text { Elasticity } \\
\text { modulus } /\left(\mathrm{N} / \mathrm{m}^{2}\right)\end{array}$ & $\begin{array}{c}\text { Poisson's } \\
\text { ratio }\end{array}$ & $\begin{array}{c}\text { Coefficient of } \\
\text { thermal expansion } \\
\left(\mathrm{m} /{ }^{\circ} \mathrm{C}\right)\end{array}$ & $\begin{array}{c}\text { Specific heat } \\
\left(\mathrm{J} /\left(\mathrm{kg} \cdot{ }^{\circ} \mathrm{C}\right)\right)\end{array}$ & $\begin{array}{c}\text { Thermal conductivity } \\
/\left(\mathrm{W} /\left(\mathrm{m} \cdot{ }^{\circ} \mathrm{C}\right)\right)\end{array}$ \\
\hline Spindle & $20 \mathrm{CrNiMo}$ & 7870 & $2.08 \mathrm{E}+11$ & 0.295 & $1.28 \mathrm{E}-05$ & 460 & 44 \\
\hline Bearing & SUJ2 & 7830 & $2.08 \mathrm{E}+11$ & 0.3 & $1.20 \mathrm{E}-05$ & 460 & 46 \\
\hline $\begin{array}{c}\text { Waterproof } \\
\text { labyrinth }\end{array}$ & HT250 & 7280 & $1.38 \mathrm{E}+11$ & 0.156 & $8.2 \mathrm{E}-06$ & 510 & 45 \\
\hline $\begin{array}{c}\text { Other } \\
\text { components }\end{array}$ & $45 \#$ & 7890 & $2.09 \mathrm{E}+11$ & 0.269 & $1.17 \mathrm{E}-05$ & 450 & 48 \\
\hline
\end{tabular}

\section{Consequences}

Steady State Thermal Analysis. The results are shown in Fig.4. In the temperature field of the spindle system, the spindle system is in thermal equilibrium. The maximum temperature of $79.422{ }^{\circ} \mathrm{C}$ and the 
location in the maximum temperature is the in the front bearing. The minimum temperature is $25.308{ }^{\circ} \mathrm{C}$ and the location is in the middle of the outer sleeve and the end of the spindle box. These areas are far away from the heat source, and the temperature field distribution is mainly to the surrounding position of the bearing to form the spindle system temperature field distribution.

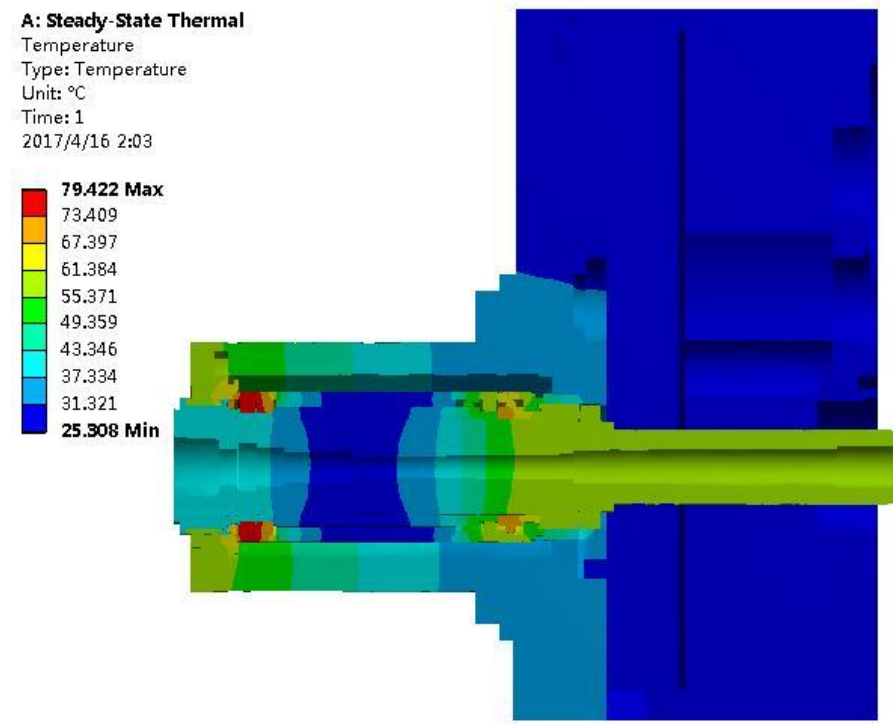

Figure 4. Steady temperature field of spindle system

Thermal Structural Analysis. The temperature field obtained by the steady-state thermal analysis of the spindle system is applied as a load on the finite element model. The spindle system is subjected to thermal structural coupling analysis by sequential coupling. The bottom of the spindle box is fixed and the gravity acceleration is added. Then the solution is analyzed and the thermal deformation of the spindle system is obtained. As shown in Fig. 5(a), the maximum deformation area of the spindle system is at the head of the spindle box.

As shown in Fig. 5(b), Fig. 5(c), Fig. 5(d), there is thermal deformation in the radial direction (X direction, Y direction) of spindle, and the maximum thermal deformation is at the head of the spindle. The thermal deformation of the spindle in the $\mathrm{Y}$ direction is symmetrical, and the maximum thermal deformation is $35.2 \mu \mathrm{m}$. But the deformation of the spindle in the $\mathrm{X}$ direction is asymmetric. The maximum thermal deformation is $90.8 \mu \mathrm{m}$. The maximum deformation of the spindle in the axial direction ( $\mathrm{Z}$ direction) is $121.99 \mu \mathrm{m}$.

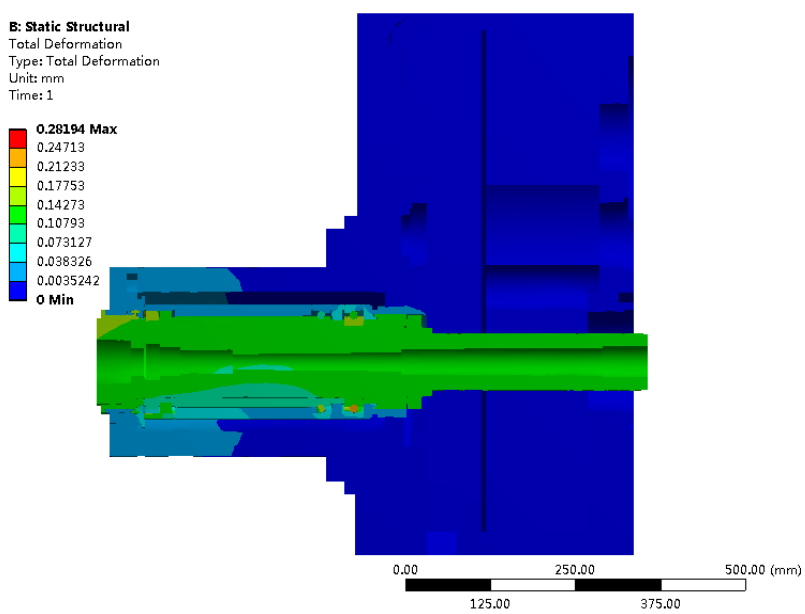

(a) Overall thermal deformation of the spindle system

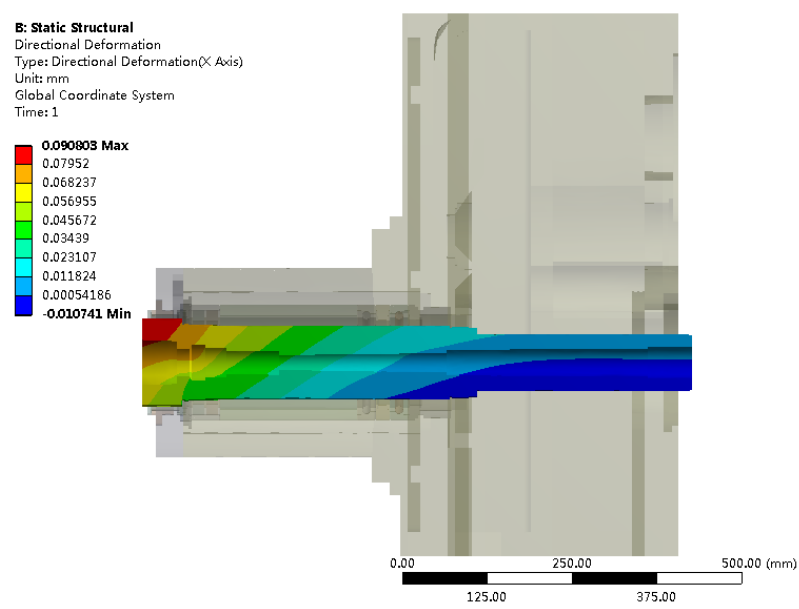

(b) $\mathrm{X}$ axis thermal deformation of spindle 


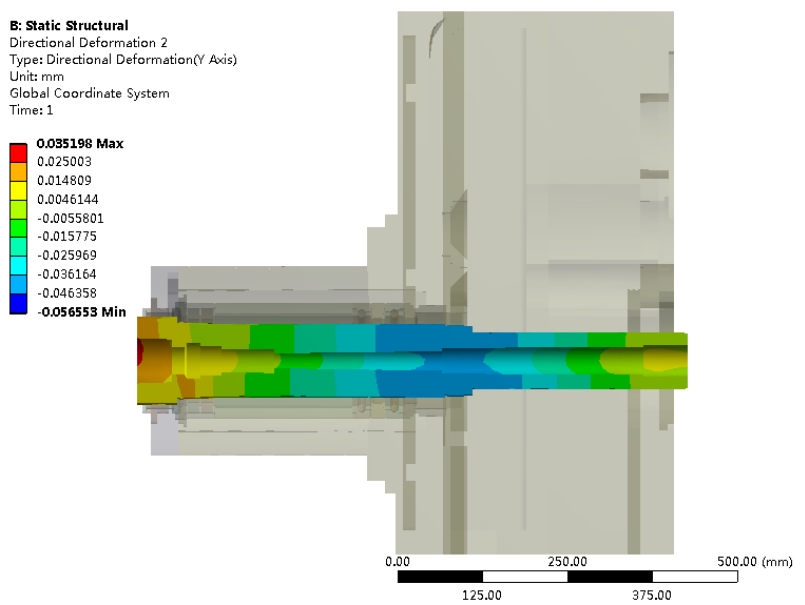

(c) $\mathrm{Y}$ axis thermal deformation of spindle

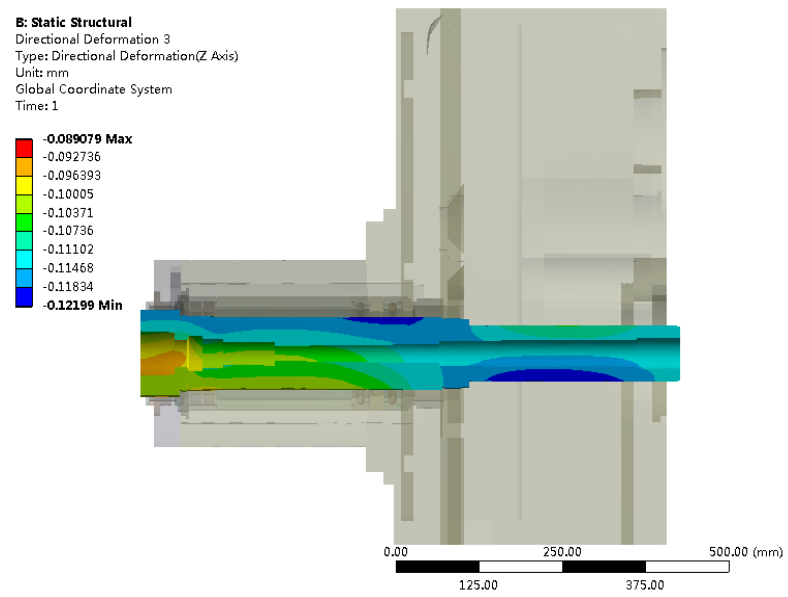

(d) $\mathrm{Z}$ axis thermal deformation of spindle

Figure 5. Thermal deformation of spindle system and thermal deformation of spindle in all directions

\section{Conclusions}

In the thermostatic analysis and thermal structure coupling analysis of the spindle system, the front bearing's temperature is the highest, and the back bearing also has obvious temperature increase. The spindle system temperature field is distributed around with the heat source.

The thermal deformation in the $\mathrm{X}$-axis is asymmetric, causing the head of the spindle rising; the thermal deformation in the $\mathrm{Y}$-axis is symmetrical; the thermal deformation in the $\mathrm{Z}$-axis is the largest, so the maximum deformation of the spindle is in the $\mathrm{Z}$-axis. The influence of machining error in the $\mathrm{Z}$-axis is the biggest.

\section{Acknowledgements}

This project is supported by the National Science and Technology Major Project, China (No. 2012ZX04005-021)

\section{References}

[1] W T Li, B H Huang: Analysis and Application of Thermal Stress Theory (China Electric Power Press, China 2004). (In Chinese)

[2] Ohishi S, Matsuzaki Y: Precision Engineering, Vol. 26 (2002) No.1, p.49.

[3] B G Zhang: Approach to Some Problems in Design and Manufacturing of High Speed Spindle with Built-in Motor. Manufacturing Technology \& Machine Tool, (2001).

[4] Z F Liu, C Y Ma and Y S Liu: Journal of Beijing University of Technology, Vol. 42(2016) No.1, p.17. (In Chinese)

[5] L Y Zou, X L Chou and Y X Zhao: Machine Tool \& Hydraulics, Vol. 41(2013) No.13, p.20. (In Chinese)

[6] X F Liu, X A Chen: Journal of Mechanical Engineering, Vol. 50(2014) No.11, p.93. (In Chinese)

[7] X X Chen, P Y Zhao: Heat Transfer and Thermal Deformation (Hunan University Press, China 1988). (In Chinese)

[8] Y Q Liang: Heat Transfer and Thermal Deformation Foundation in Mechanical Manufacturing (China Machine Press, China 1984). (In Chinese) 
[9] C Guo, Q H Kong and S Y Jiang: MANUFACTURING TECHNOLOGY \& MACHINE TOOL, (2003) No.3, p.37. (In Chinese)

[10] Harris, T. A., Kotzalas, M. N.: Analysis of Rolling Bearing(China Machine Press, China 2009). (In Chinese)

[11] G L Xu: Engineering heat (China Electric Power Press, China 2011) (In Chinese)

[12] S N Ding: Heating and Cooling of Large Electrical Machines (Science Press, China 1992). (In Chinese) 